\title{
Identification, Challenges and Ways of Addressing (Geo)ecological Risks at the Regional Scale
}

\author{
Anatoly K. Arabsky ${ }^{1, *}$ and Vladimir N. Bashkin ${ }^{2,3}$ \\ ${ }^{I}$ Gazprom Dobycha Yamburg LLC, N-Urengoy, YANAO region, Russia \\ ${ }^{2}$ Gazprom VNIIGAZ LLC, Razvilka, Leninsky District, Moscow Region, 142719 Russia; \\ ${ }^{3}$ Institute of Physicochemical and Biological Problems of Soil Science RAS, Pushchino, Moscow Region, 142292 Russia
}

\begin{abstract}
The paper is addressing the development of the gas and oil resources in polar areas that nowadays is impossible without the efficient settlement of environmental issues. The main topic is also the development of regional-branch environmental management system in the Yamalo-Nenets Autonomous Okrug (YNAO), including the potential application of strategic environmental assessment (SEA) to speed up economic development of the Yamalo-Nenets Autonomous Okrug.
\end{abstract}

Keywords: Geoecological risks, polar areas, regiona scale, regional management.

\section{INTRODUCTION}

Currently a lot of attention in the areas of gas industry is being drawn to the sustainable development. Addressing to the regional pattern of joining affords to environmental protection the areas of gas and oil production in the Polar area, one should emphasize the thesis that development of these resources is impossible without the efficient settlement of environmental issues (Arabsky et al., this issue). At the same time nothing can be resolved separately without concerted efforts of any company or agency. Arctic resources may only be developed upon the harmonious alliance of all the stakeholders via generally accepted principles of sustainable development and social responsibility (Andreev et al. 2004, 2010; Bashkin et al. 2013; Bashkin 2014; Ishkov et al. 2010, 2011; Salikhov et al. 2010). This will require practical implementation of the Strategic Environmental Assessment (SEA) and the Regional-Branch Environmental Management System (RBEMS) making them practical and adaptable to the present-day conditions in Russia (Sustainable... 2013). The environment-based research and development activities of the enterprises will enable to meet these challenges and tackle various problems not only at the level of agencies but at the regional scale as well.

Accordingly, the purpose of this paper is to show concept ideas for Regional-Branch Environmental Management System (RBEMS) and to analize the ways of their practical implementation in Polar Regions of Russia.

\footnotetext{
*Address correspondence to this author at the Gazprom Dobycha Yamburg, LLC: Dr (tech) Anatoly K. Arabsky, Deputy Chief Engineer, Gazprom Dobycha Yamburg, LLC, N-Urengoy, YANAO Region, 629306 Russia; Tel/Fax: +734494966015, E-mail: A.Arabsky@ygd.gazprom.ru
}

\section{REGIONAL-BRANCH ENVIRONMENTAL MAN- AGEMENT SYSTEM IN THE YAMALO-NENETS AUTONOMOUS OKRUG (YNAO)}

Being guided by its social responsibility, Gazprom Dobycha Yamburg, LLC has launched an initiative to set up the Regional-Branch Environmental Management System (RBEMS) in the Yamalo-Nenets Autonomous Okrug. The Memorandum on Hydrocarbon Fields Development on the Yamal Peninsula and in Adjacent Water Courses signed in 2002 by the Yamalo-Nenets Autonomous Okrug Administration and Gazprom JSC triggered this effort. To this end, R\&D works were performed to develop the RBEMS concept, which has the following key goals (Ishkov et al. 2010):

1 to design and implement the regional-branch environmental policy (harmonized with the interests of all the system stakeholders);

2 to coordinate actions of executive state government bodies, territorial government bodies, enterprisesusers of natural resources in the fuel and energy industry, NGOs and environmental institutions;

3 to work out mechanisms for environmental adverse impact minimization, cost optimization in the sphere of environmental protection and cost-effective use of resources and energy saving, etc.;

4 to optimize the environmental management functions by joining coordinated efforts of all RBEMS members;

5 to improve legal-regulatory framework and organizational-administrative documentation in the sphere of environmental protection on the regional and federal scales; 


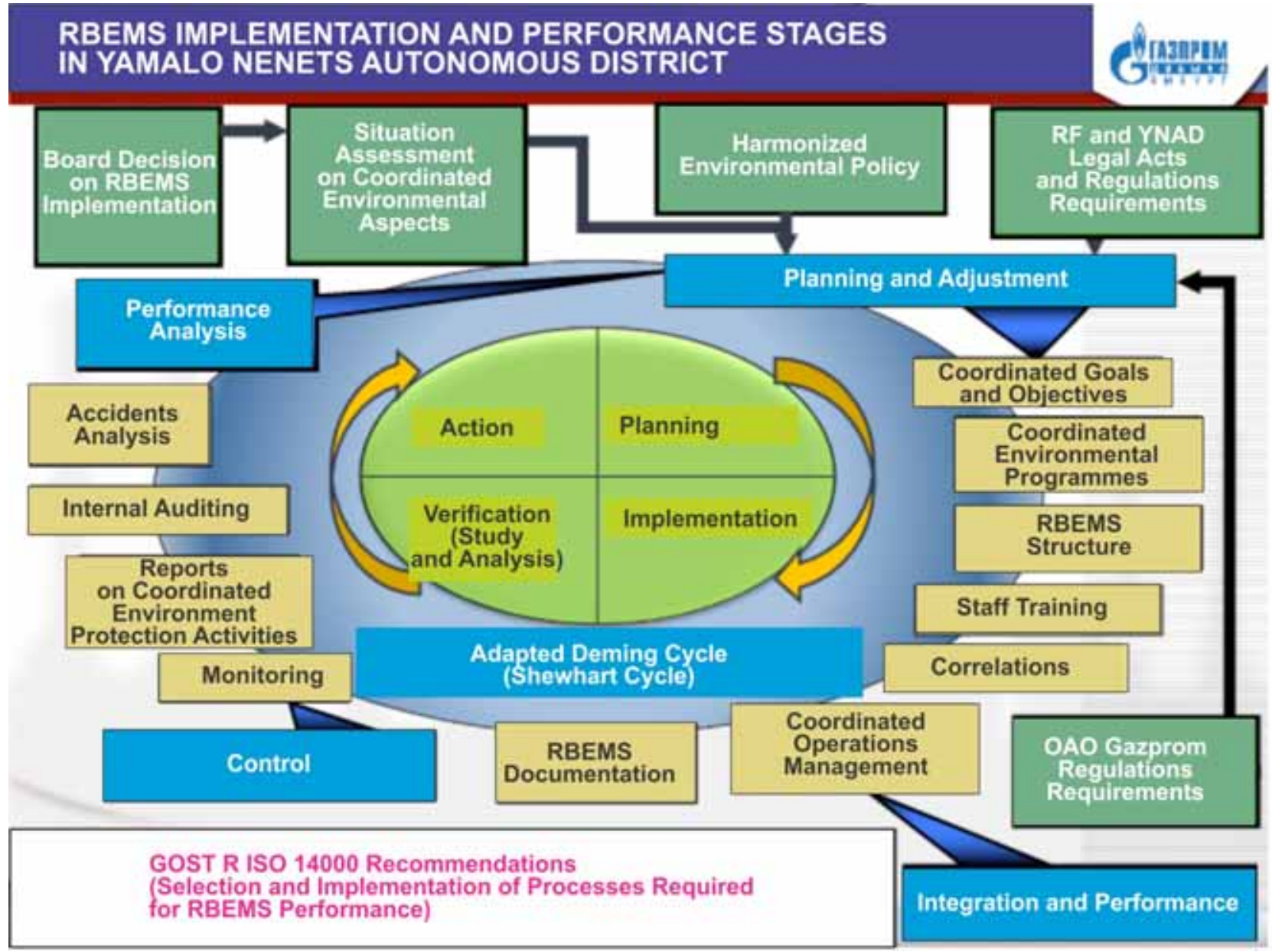

Fig. (1). Deming Cycle adapted for the Regional-Branch Environmental Management System in YNAO (Yamalo-Nenets Autonomous Okrug).

RBEMS - Regional-Branch Environmental Management System;

GOST R ISO - the Russian version of ISO (International Standards Organization).

6 to enhance transparency level in the sphere of natural resources exploitation and environmental protection, to provide reliable information to the population, economic entities, public organizations and government authorities.

RBEMS is meant to be an organizational management system (system of management and control over environmental protection efforts, as determined by GOST R ISO 9000) established on the basis of legal-regulatory documents and information technologies. Thus, the R\&D effort incorporated certain fundamental principles embedded in the ISO 14000 international standard for development and integration of the environmental management system. The $R \& D$ also relied on the fundamental principles of sustainable gas industry development, established and proposed by the International Gas Union, and social accountability principles integrated into ISO 26000 international standard of 2010 "Guidance on Social Responsibility of Enterprises".

The RBEMS functioning mechanism is based on the RF GOST R ISO 14000:2007 national standard, which is harmonized with the ISO 14000-2004 standards and implies regular analysis and assessment of management and admini- stration results carried out by the system stakeholders. It determines ways and ensures comprehensive optimization of environmental protection in the Yamalo-Nenets Autonomous Okrug, and find ways to ameliorate the environmental conditions. The result should be a permanent modernization of environmental activities in the area via the generally accepted management model, which consists of 5 key elements: 1) environmental policy, 2) planning, 3) implementation, 4) measurement and assessment, and 5) analysis and modernization.

The RBEMS operates in compliance with the enterprise environmental management system described in ISO 14000 standards. One crucial difference is that the RBEMS fundamental provisions shall be agreed upon by all the stakeholders starting from a common policy formulation based on the regional and enterprise policies.

The key condition for RBEMS functioning and improvement is its "permanent modernization" described in Deming cycle adapted to the given task and shown in Fig. (1). The above goal may be attained due to a strong inverse feedback of the RBEMS in the course of its performance thus ensuring its stability. 
Once RBEMS is in place, its member organizations should assess its environmental effectiveness via compliance with the requirements instituted quantitatively in their internal and concurred policies as well as in goals and projected indicators.

This will contribute to the higher accuracy of geoenvironmental risks quantitative assessment, provide ways of RBEMS modernization and clarify the environment-related performance of enterprises. These efforts will enable to adjust the systems performance and eliminate causes of its incompliance with the specified concurred requirements.

\section{POTENTIAL APPLICATION OF STRATEGIC ENVI- RONMENTAL ASSESSMENT (SEA) TO SPEED UP ECONOMIC DEVELOPMENT OF THE YAMALO- NENETS AUTONOMOUS OKRUG}

Gas and oil projects implementation in the Russia's Arctic shelf has a number of specific features related to environmental aspects of hydrocarbon fields exploration, infrastructure development and operation:

1 Natural conditions in the Arctic provinces, particularly shore lands are highly sensitive to man-induced impact. The Barents Sea and other Seas of Arctic have a huge potential in terms of aquatic biological resources and biodiversity. The Ob-Taz Bay stands apart being a unique freshwater body. It ensures northern rivers flow into the Arctic Ocean including the $\mathrm{Ob}$, the Taz and the Nadym. Their aquatic area and shores are highly sensitive to various disturbances, including man-induced disturbances and thus, rehabilitate with great difficulty. Moreover, this is the realm of unique fishery resources, such as whitefish (muksun), nelma and other precious species including sturgeons.

2 The Arctic shore is a natural habitat for indigenous ethnic minorities, and traditionally their nature use fully depends on biological resources of the area and may be easily damaged by inappropriate interference.

3 Almost all the projects implemented in these provinces have international context, partly due to engagement of foreign companies and financial institutions and partly due to trans-boundary nature of the offshore zones of the Arctic Ocean and the countries around it.

The aforementioned facts necessitate a special comprehensive approach to managing environmental and social aspects of the policy, strategy and plans vis-à-vis implementation of oil and gas projects both in the Arctic shelf and coastal territories. It is quite obvious that such an approach is feasible, provided that all the stakeholders are engaged and further monitoring ensued at all levels from the regional to the Russian scale. Such approach relies on the UNECE Convention on Environmental Impact Assessment in a TransBoundary Context signed in Espoo on February 25, 1991 and Protocol on Strategic Environmental Assessment signed in Kiev on May 21, 2003. The Protocol became effective on July 11, 2010 as one of the UN documents signed by first 35 countries. At present it is open for signing by other countries.
Accordingly the President signed a series of mandates on environmental improvement in the Russian Federation (Rossiyskaya Gazeta, 21.06.2011). The mandates include:

- instruction to the government to ratify the UNECE Convention on Environmental Impact Assessment in a Trans-Boundary Context;

- instruction to intensify Russia's contribution in international cooperation in the sphere of environmental safety control in developing natural resources of the Arctic, Pacific, Caspian, Black Sea and the Baltic regions, covering implementation of joint programs with stakeholders, international organizations and financial institutions.

In this respect, the Yamalo-Nenets Autonomous Okrug with its rapid oil-and-gas industry development is designated to pioneer this trend in Russia relying on best practices of the global community. For this it has all the prerequisites, which can be proved right away.

Each new field in Russia today has a specially designed development project. In pursue to legislative requirements, hydrocarbon field lifecycle is imperatively tied up to environmental impact assessment (EIA) drawn up as a standalone document in design documentation and as a part of its project development. EIA development and approval processes are schematically shown in Fig. (2).

The Environmental Impact Assessment is developed on the basis of data obtained from lifecycle surveys at the stage of pre-project exploration. They serve to initialize infrastructure project development. It is at this stage that the general public is involved in the potential risks assessment of the future project. Its opinion is registered and compensatory activities are determined for minimizing the environmental damage from the upcoming project, estimating the damage extent and specification of recovery procedures.

However, it would hardly be appropriate to assert that such an approach is rational for each particular field. It is obvious that the optimized environmental approach to large groups of similar fields' development requires a comprehensive method of general environmental assessment at the stage of pre-project exploration, excluding random or systematic errors. Precisely this approach is recommended in the Protocol on Strategic Environmental Assessment developed and prepared for signing in 2003 and registered as the UN document in 2010. Its key goals are:

- to accurately account for environmental issues and those related to public health at the development stage of plans and programs subject to approval by the Parliament or the government;

- to facilitate the review procedure vis-a-vis environmental and public health concerns at the stage of shaping policies and legislation;

- to establish clear, transparent and efficient procedures of strategic environmental assessment;

- to ensure involvement of the general public into the strategic environmental assessment; 


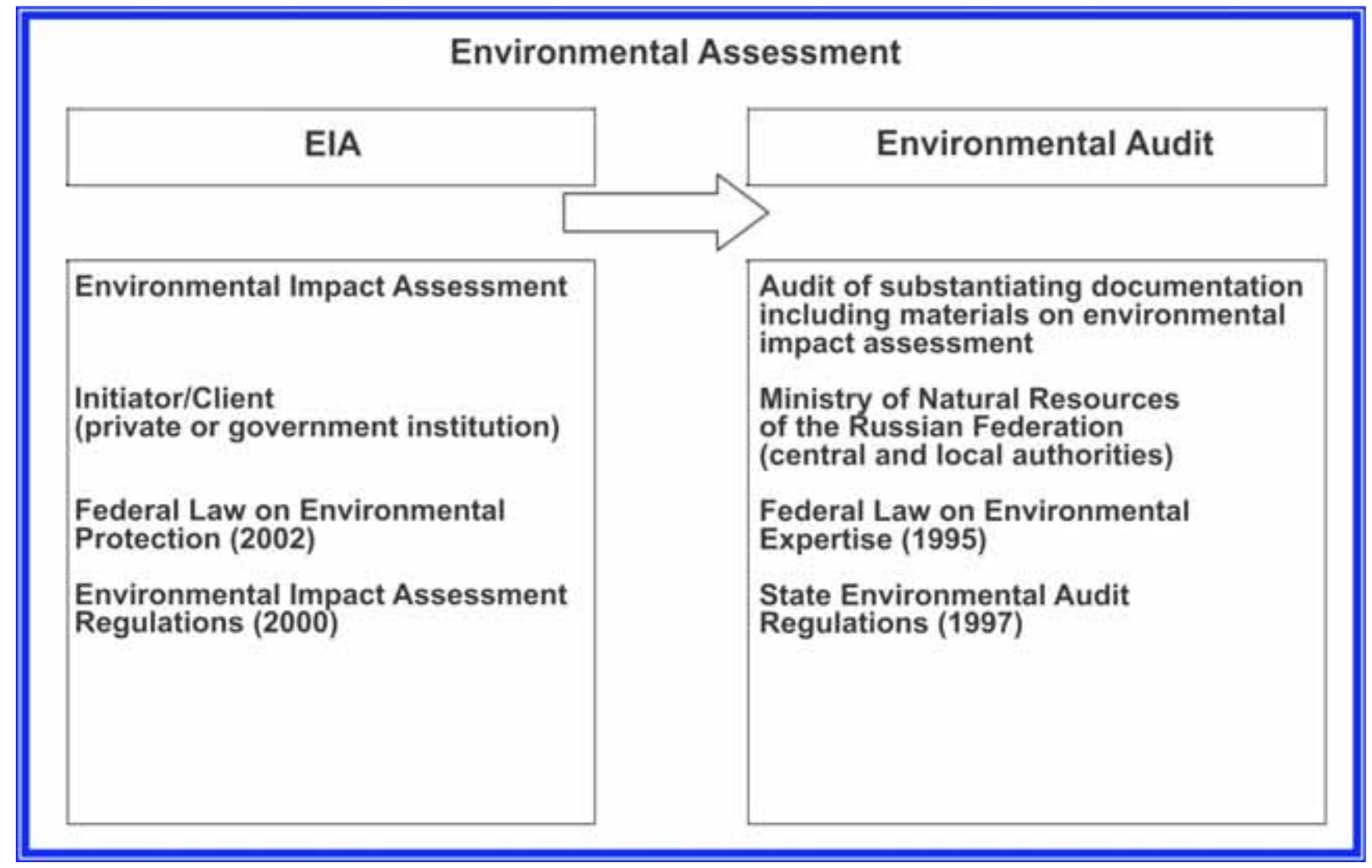

Fig. (2). EIA development and approval.

- $\quad$ to integrate the environmental and public health concerns into measures and documents structured to ensure sustainable development.

Attempts made in Russia to implement the Protocol procedures were a failure. However, it's not the subject matter of our discussion and the reasons will become obvious at the latest stage. Meanwhile, it worth taking an insight into the research work implicitly related to this trend.

To date, Gazprom VNIIGAZ, LLC and JSC Gazprom subsidiaries, jointly with the DIEM Scientific Production Company have accumulated considerable experience in environmental assessment of projects development at various stages, as well as in environmental tracking of geological survey and hydrocarbon field infrastructure development offshore and on the coasts of the Ob-Taz Bay. A series of R\&D activities have been implemented or are underway in the environmental context. All of them have an applied, scientific and strategic nature. "Guidelines on Selecting and Applying Criteria for Retrospective-Predictive Assessment of the Geo-Environmental Situation at Hydrocarbon Fields in the Far North" are to be drawn up in 2012, while two years ago the concept of the Regional-Branch Environmental Management System (RBEMS) for YNAO was put forth.

The results obtained in this and other research works substantiate a comprehensive systemic approach to ensure environmental safety at all stages of project implementation. And this conclusion fully complies with the Protocol on Strategic Environmental Assessment to the Convention on Environmental Impact Assessment in a Trans-Boundary Context.
A distinctive feature of the Protocol is that it may be applicable to major regional strategic projects, including offshore hydrocarbon production. Taking into account the geographical location of hydrocarbon fields under development, in the wake of development or prospective fields in YNAO, an independent Strategic Environmental Assessment (SEA) is needed for the Yamal Peninsula along the Kara Sea shelf and the Ob-Taz Bay. It is also necessary to start SEA development for the Gydan Peninsula.

The Protocol defines "Strategic Environmental Assessment" for probable environmental implications including public health-related component, strategic policy development and potential projects implementation on the local or national scale to be presented in an environmental report. The SEA involves identification of the environmental report scope and principles of its compiling which presupposes general public involvement and expressed public opinion. At the same time it guarantees that all the environmental report provisions and public opinion will be taken into account in the plan of strategic development policy or the program of potential projects implementation long before the project is launched.

Such an approach enables to set up an integrated feasible concept of environmental safety on the local scale and determine the key requirements and conditions on the plans and programs of hydrocarbon fields' exploration and development including offshore in collaboration with different companies. 


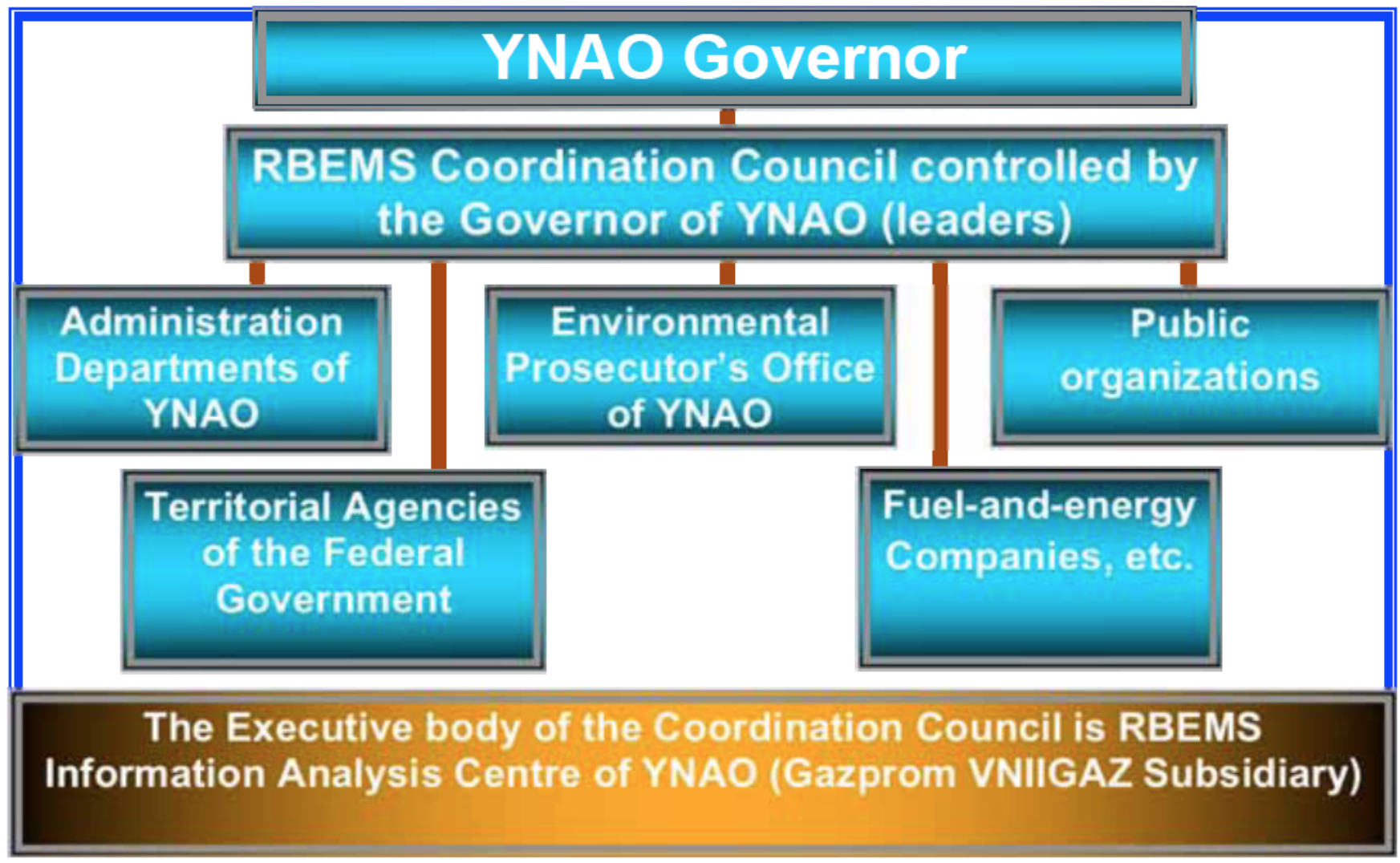

Fig. (3). Structure of the RBEMS Coordination Council controlled by the Governor of YNAO.

The environmental report pursuant to Article 7 of the Protocol defines, describes and gives material assessment of probable essential environmental implications and its public health-related component of the plan or program or their reasonable alternatives implementation. It also provides a considerable amount of backup information which might be required for certain projects implementation. (The list of the backup information may be found in the Protocol Annexes). Nevertheless, it's worthy to interpret the Protocol Annex on "Environmental Implications and its Public Health-Related Component". They imply any implications on the environment and those which may affect the public health, flora and fauna, biodiversity, soils, climate, air, water, landscape, natural objects, tangible assets, cultural heritage and interaction of these factors.

The scope of clearly set goals falls beyond the competence of each particular administrative and government structure, not to mention business companies. That is why all the attempts to introduce SEA, especially for individual business companies under their own initiative have so far failed in Russia. Naturally, the question arises of whether YNAO will be able to clear this barrier?

\section{Our answer is an affirmative one: Yes! We will be able!}

Our confidence stems from the fact that the Company has elaborated the concept for establishing the Regional-Branch Environmental Management System (RBEMS) in YNAO. This concept presupposes establishment of the Coordination Council controlled by the Governor and to be attended by the heads of the Administration departments, territorial agencies of the federal government, major fuel-and-energy compa- nies, nature conservation NGOs and organizations representing the interests of indigenous population in YNAO, nature conservation prosecutor's office, etc. The structure of the Coordination Council of the Yamalo-Nenets Autonomous Okrug is shown in Fig. (3).

Speaking in terms of GOST R ISO 9000 and 14000, RBEMS is supposed to be a system of administration, planning and management of the environmental situation in all its diversity on the local scale in the course of implementing short-term, mid-term and long-term plans of its strategic development.

The principal difference of this system from the EMS established on the basis of GOST R ISO 14000:2008 recommendations is that the enterprises all over the world have been, are and will be engaged in environmental protection at their licensed sites. This is a much narrower field of activity versus goals to be attained in the course of regional development and which actually fall into the set of notions on ecology, natural and social environment. Thus, this is a set of tasks to be fulfilled in terms of the Regional-Branch of Environmental Management System of the District, and this is its fundamental difference from other EMS of enterprises.

The RBEMS structure shown in Fig. (1) directly indicates that RBEMS is designated to supervise the environmental report compilation in accordance with the Protocol on "Strategic Environmental Assessment" which is the UN document, and approve the report as the District Document. RBEMS will sanction all EIA projects and Environmental Expert Review provided that their parameters comply with the assessment given in the Environmental Report. The 
RBEMS of the Yamalo-Nenets Autonomous Okrug shall introduce proposals to revise the environmental report baseline provisions on "Strategic Environmental Assessment" in the following cases:

$>$ identification of principally new circumstances of the environmental situation development in the District;

$>$ identification of critically new essential transboundary environmental aspects;

$>$ detection of substantial and controversial problems with alternative options for at least one specific strategic projects at the lifecycle stage - design works;

$>$ market launch of brand new equipment and technologies enabling to put forth positive radical changes of the environmental situation of the District in the course of its strategic development plans implementation.

Hence it's just logical to highlight other RBEMS challenges of YNAO, namely:

$>$ recommend an updated list of Russian and foreign standards on environmental protection out of best criteria of compliance to be applicable in the District;

$>$ consider comprehensive regional development programs in the sphere of cost-effective use of energy and resources, environmental protection and social policy;

$>$ supervise an updated list of the best available technologies, including field exploration and infrastructure development of the Arctic seas shelf and the ObTaz Bay.

This is just a list of short-term challenges in the oil and gas sector of the District economy that would be extremely hard to address without RBEMS. Thus, they should meet the requirements and recommendations on the global scale, including the UN Protocol on "Strategic Environmental Assessment". RBEMS relevance will increase significantly upon implementation of the Ural Polyarny Project, which is scheduled for the Yamalo-Nenets Autonomous Okrug.

\section{CONCLUSION}

At the International Arctic Forum "Arctics - the Territory of Dialogue" held on September 22-23, 2010 in Moscow the Governor of the Yamalo-Nenets Autonomous Okrug Dmitry Kobylkin mentioned that field development projects at the Yamal Peninsula, "Ural-Promyshlenny - Ural Polyarny" are the key components of turning the Arctic into resource base of the $21^{\text {st }}$ century. The Russian Arctic today:

1 ensures $11 \%$ of the national income of Russia;

2 comprises $22 \%$ of Russian exports;
3 extracts $90 \%$ of nickel and cobalt, $60 \%$ of copper, $96 \%$ of platinum-group metals;

4 enjoys commercially productive alluvial assets of gold, stream tin, diamonds;

5 provides the shortest way from Europe to the USA and Asia - the Northern Sea Route.

For better understanding and future development of these features we will require practical implementation of the Strategic Environmental Assessment (SEA) and the RegionalBranch Environmental Management System (RBEMS). These allow us to meet above-mentioned challenges in the Polar Regions.

\section{CONFLICT OF INTEREST}

The authors confirm that this article content has no conflict of interest.

\section{ACKNOWLEDGEMENTS}

The authors express their deep appreciation and gratitude to Dr. O. Makluk, head of environmental protection department of Gazprom Dobycha Yamburg LLC, and Administration of Yamalo-Nenets Autonomous Okrug, YNAO, for helpful discussion and useful support.

\section{REFERENCES}

Andreev, OP, Stavkin, GP, Levinzon, IL, Perepelkin, IB \& Lobastova, SA (2003) Soils and landscapes protection and restoration at the stage of gas production in the far north. Ecology and Industry of Russia, 6, 4-9.

Andreyev, OP, Mazanov, SV, Akhmedsafin, SK, Arabsky, AK, Ishkov, AG, Rusakov, SY \& Yarygin, GA (2010) Environmental safety issues at the stage of first gas fields development in the Ob-Taz Bay. Science and Technology in Gas Industry, 4, 32-8.

Bashkin, VN, Arno, OB, Arabsky, AK, Barsukov, AV, Priputina, IV \& Galiulin, RV (2013) Retrospective and Prognosis of Geoecological Situation in the Gas-condensate Fields of the Polar Regions, Gazprom VNIIGAZ, Moscow.

Bashkin, VN (2014) Biogeochemistry of Polar Ecosystems in the Impacted Zones of Gas Industry, Gazprom VNIIGAZ, Moscow.

Ishkov, AG, Andreyev, OP, Arabsky, AK, Yarygin, GA, Khvastina, AS \& Bayukin, MV (2010) Key principles of the regional-branch environmental management system. Environment Protection in Oil and Gas Complex, 4, 4-9.

Ishkov, AG, Yarygin, GA, Kuzmin, YO, Lukyanov, OV \& Farafonov, AS (2011) Present day geodynamic hazards assessment at the stage of trunk pipelines design and construction. Science and Technology in Gas Industry, 1, 66-71.

Salikhov, ZS, Mazanov, SV, Kumushbayev, AM \& Kozlov, VM (2010) Operating Hazardous production facilities at gazprom dobycha yamburg, LLC in the far north. Gas Industry, 8, 74-7.

Markelov, VA, Andreev, OP \& Kobylkin DN, (2013) (Eds.) Sustainable Development of Gas Industry, Nedra, Moscow.

Received: November 22, 2014

Revised: February 01, 2015

Accepted: March 24, 2015

(C) Arabsky and Bashkin; Licensee Bentham Open.

This is an open access article licensed under the terms of the Creative Commons Attribution Non-Commercial License (http://creativecommons.org/ licenses/by-nc/3.0/), which permits unrestricted, non-commercial use, distribution and reproduction in any medium, provided the work is properly cited. 